\title{
Research on Environmental Tax With Emphasis on Developing Renewable Energy in Beijing, China
}

\author{
Yu Zou ${ }^{1}$, Shanshan Wang ${ }^{1}$, Takeshi Mizunoya ${ }^{1}$, Helmut Yabar $^{1} \&$ Yoshiro Higano ${ }^{1}$ \\ ${ }^{1}$ Graduate School of Life and Environmental Sciences, University of Tsukuba, Japan \\ Correspondence: Yu Zou, Graduate School of Life and Environmental Sciences, University of Tsukuba, 1-1-1 \\ Tennodai, Tsukuba, Ibaraki 305-8572, Japan. Tel: 81-29-853-7255. E-mail: zouyu0504@hotmail.com
}

Received: December 3, 2013

Accepted: February 22, 2014 Online Published: March 11, 2014

doi:10.5539/jsd.v7n2p78

URL: http://dx.doi.org/10.5539/jsd.v7n2p78

\begin{abstract}
Development of renewable energy is considered as an effective measure to control greenhouse gas emissions in the world. Policy instrument to promote development of the renewable energy have been paid more and more attention. As the most industrialized and urbanized region, Beijing plays as a demonstration role to show the impact of environmental policy instrument on the development of renewable energy and the mitigation of GHG emissions. In this paper, based on the input-ouput table, we constructed a dynamic input-output model introducing renewable energy industries, as well as the invironmental policy instrument of the emission tax. It not only can explore the relationships among Beijing's renewable energy, economy and environment, but also can analyze the future trends of the economy and GHG intensity from 2010 to 2025 . The objective function is the maximized GRP, subject to greenhouse gases emissions constraint and some subjective functions. The simulation results illustrated that with the GHG emissions constraint as 1.5 times of the 2010 level, carbon tax as $80 \mathrm{CNY} / \mathrm{t} \mathrm{CO}_{2}$-e is effective to promote the renewable energy development, economic development and GHG emissions mitigation. Annual growth rate of GRP can be up to $6.4 \%$. The economic growth rate increases $0.6 \%$ compared with the condition when not introducing the policy instrument. In 2025, the GHG intensity will be 41.8 t CO$_{2}$-e/million CNY, 41.4\% reduced compared with the 2010 level. Total power generation of renewable energy can be $40.9 \mathrm{GWh}$, contributing to the reduction of 25 million $\mathrm{CO}_{2}$-e emissions in 15 years. This research proves that the proposed environmental policy instrument is effective to realize the government's targets.
\end{abstract}

Keywords: renewable energy, GHG emissions, input-out model, carbon tax

\section{Introduction}

The share of renewable energy is increasing every year in the global energy consumption (Potočnik, 2007). Renewable energy sources make a big reduction in the emission of greenhouse gases, improvement of energy security and promotion of sustainable development (Dincer, 2000). In China, around 18\% of the country's population lived in the top 35 large cities and the share of these cities was around $40 \%$ in the energy utilization and $\mathrm{CO}_{2}$ emission of China in 2006 (Dhakal, 2009). They shall play crucial roles in determining the future path of energy consumption and carbon emissions in China that meets the international commitment of reduction in GHG emissions made by the Central Government. Energy and environmental policy instrument adopted by those cities would be of great significance in achieving the national targets such as energy security and climate change mitigation (Zhang, Feng, \& Chen, 2011). Among them, Beijing is the most industrialized and urbanized region in China. Conducting studies of Beijing's energy-related carbon emission will both help the Central Government to formulate nation-wide emission-reduction measures and provide a role model for the rest of the country to emulate (Zhang, Zhang, Yang, Fath, \& Li, 2013). In 2011, Beijing firstly issued the "12th Five-Year Plan of New and Renewable Energy Development" (Beijing Municipal Commission of Development and Reform, 2011a) in order to enhance the utilization of renewable energy and reduce the carbon emission. The electricity and heating industry had the biggest share (28.5\%) in the $\mathrm{CO}_{2}$ emission by industries in 2010. It is urgent to increase the share of renewable energy by reducing the consumption of fossil-oriented energy sources in the electricity and heating industry in order to decrease $\mathrm{CO}_{2}$ emission. In this paper, we constructed an extended input-output model into which renewable energy industries and the economic policy instrument of the emission tax are introduced, so as to analyze the effects of the environmental tax on reducing $\mathrm{CO}_{2}$ emission and promoting 
eonomy, and to manifest if the environmental economic policy instrument is effective to realize the government's targets.

There are many models to explore the relationships among the energy, economic development and environmental protection in the world. CGE (Computable general equilibrium) Model emphasizes the interaction between different economic departments and accurately describes the relationship between the energy sectors and other economic sectors. Liang and Wei (2012) compared the impacts of different carbon tax schemes on household disposable income, household welfare, economic growth, and $\mathrm{CO}_{2}$ emissions with a recursive dynamic CGE model. TIMES economic paradigm computes an inter-temporal dynamic partial equilibrium on energy and emission markets based on the maximization of total surplus. TIAM-World, which is based on the TIMES, was developed by many authors and used in many international and European projects (Labriet, Kanudia, \& Loulou, 2012). Rout et al. (2011) developed key energy indicators, which are used to project energy service demands and emissions forward for China in TIMES G5 model, to forecast the demand and the associated emissions by the end of the $21^{\text {st }}$ century. The current focus on global energy and energy price volatility high lights the importance of a sound econometric basis for key energy parameters used in CGE models, such as the GTAP-E model (Beckman, Hertel, \& Tyner, 2011). Input-out model has been recognized as a useful top-down approach for policy analysis and resources accounting (Wiedmann, 2009). Uchida and Higano (2006) constructed an extended input-output table including virtual industries and developed a comrenhensive methodology in three view points of value balance, energy balance and material balance to evaluate the impacts of policy instruments such as taxes and subsidies.

Environmental tax to affect the economy and environment has become a hot issue in economic research. Wei et al. (2011) analyzed the impact of the introduction of environmental tax based on tax economics from micro and macro level. Lu et al. (2010) constructed a dynamic recursive general equilibrium model to analyze the impact of carbon tax on Chinese economy in the long term. Yang et al. (2011) analyzed the impacts of carbon tax on Chinese macroeconomics, it get the optimal fixed carbon tax as $8.84 \mathrm{CNY}_{\mathrm{t} \mathrm{CO}}$-e and $17.99 \mathrm{CNY}_{\mathrm{t}} \mathrm{CO}_{2}-\mathrm{e}$ in different constraints. They mainly analyze the impact of carbon taxe on the whole country's economy and GHG reduction, however few papers focus on the impact of environmental tax for the individual regions.

The objectives of this study are to:

(1) construct an extended input-output evaluation model and introduce renewable energy industry and the economic policy instrument of the emission tax into the simulation model.

(2) analyze the effects of the policy instrument on reducing $\mathrm{CO}_{2}$ emission and promoting new industries and expect to prove that the environmental economic policy instrument is effective to achieve the targets proposed by the government.

(3) focus on Beijing city to detect the impact of carbon tax on renewable energy development, economic development and environmental preservation, expecting to help the Central Government to formulate nation-wide tax and provide a role model that can be taken reference by the other regions to adopt the environmetal policy instrument to promote the utilization of renewable energy and mitigate the GHG intensity.

\section{Method}

In this study, the simulation is finished by LINGO, which is a programming language for solving linear, nonlinear and integer optimization problems. We constructed a dynamic simulation model based on input-output theory. In economics, an input-output model is a quantitative economic technique that represents the interdependencies between different branches of a national economy or different regional economies (Raa, 2009). It can provide a consistent analysis framework and identify the contribution of related activities through inter-industry links in the economy, input-output model is a popular tool for policy evaluation in many nations (Oliveria \& Antunes, 2004).

\subsection{Model Framework}

In this study, the dynamic simulation model is based on input-output table, including an objective function and some subjective functions. As indicated in Figure1, the objective function is to maximize the total GRP from 2010 to 2025. Subjective functions include material flow balance, value flow balance, electricity supply-demand balance and investment-saving balance. 


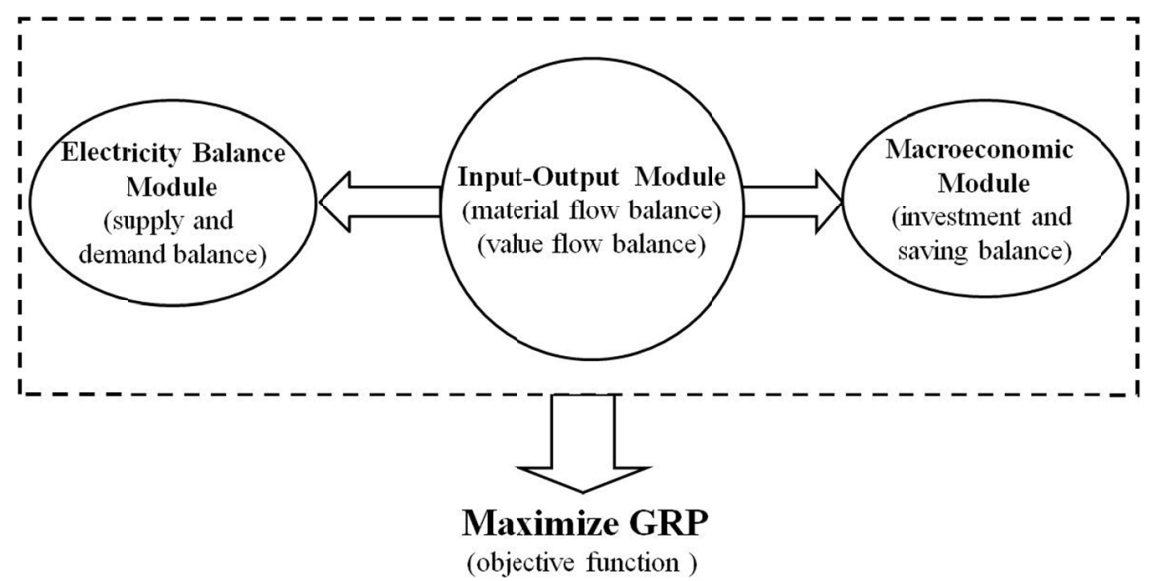

Figure 1. Model framework

Three economic subjects (industries, households and the government) are set in this model. Figure 2 shows the material flow and electricity flow between each entity. The materials include commodities, municipal waste and greenhouse gases. Commodities are consumed by each economic subject. Wastes generate from household and are transferred to the biomass power sectors. GHG are emitted by the industrial sectors and household. Electricity production industries provide power to usual industries and household. In this model, it is expected to utilize the renewable energy to reduce the GHG emissions from the consumption of fossil fuels in thmeral power industry.

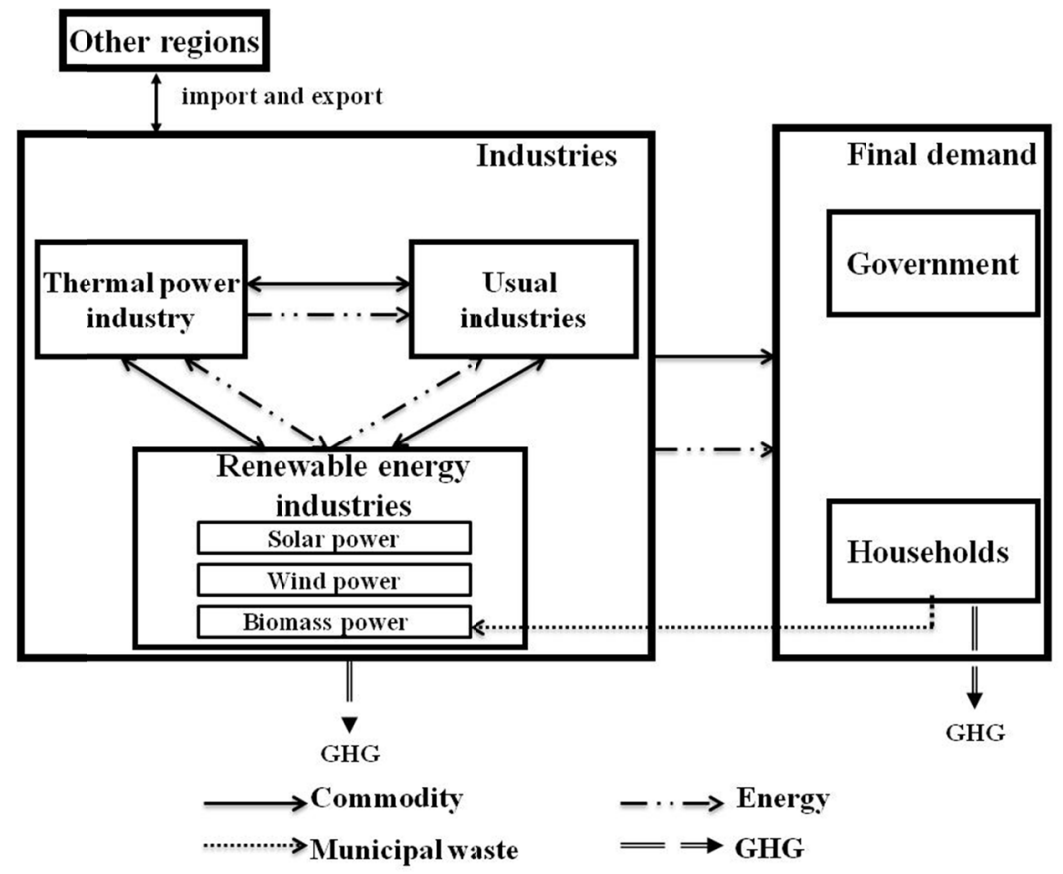

Figure 2. Material flow and electricity flow

Figure 3 shows the value flow. Household income includes the household savings, income tax and household consumption. Government revenue includes income taxes and indirect taxes. Government revenue is used for governmental purchase and governmental savings. Carbon tax is levied from thermal power industry and usual industries, which is considered as subsidy to promote the development of renewable energy industries. Finally, household savings, government savings and net exports are used as industrial investment to promote industrial development. 


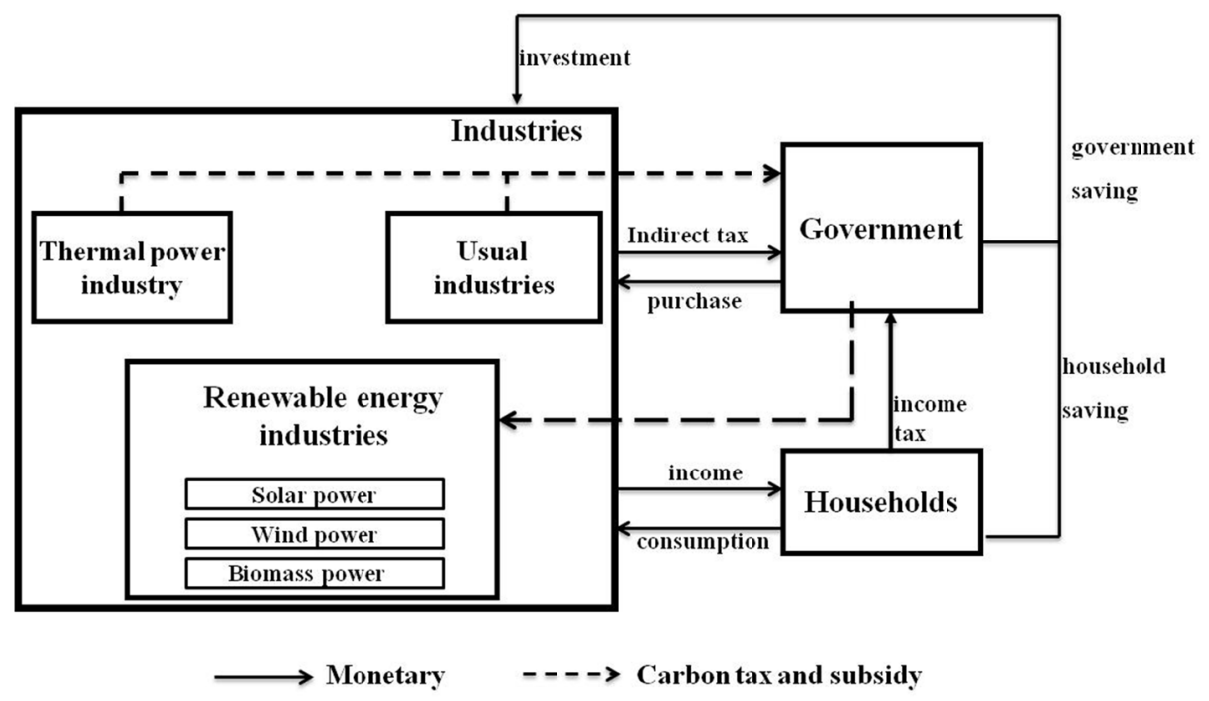

Figure 3. Value flow

In this paper, there are three industries and 19 sectors in the model (Table 1).

Table 1. Classification of industries

\begin{tabular}{cccc}
\hline Industry & & \multicolumn{2}{c}{ Sector } \\
\hline Usual industries & Agriculture & Chemical industry & Foods, tobacco and textiles \\
& Mining & Production of gas & Manufacture and equipment \\
& Construction & Petroleum and coking & Production of oil and nature Gas \\
& Services & Heat industry & Transport, storage and postal \\
& Metal products & Production of water & Production of coal \\
Thermal power industry & Thermal power & & Wind power \\
Renewable energy industries & Biomass power & Solar power & \\
\hline
\end{tabular}

\subsection{Simulation Model Formulation}

There are two types of variables: endogenous (en) and exogenous (ex). The exogenous variables are obtained from the base year data, and the endogenous variables are calculated through simulation. Subscript u represents the usual industries, subscript e represents the thermal power industry, and subscript $r$ represents the renewable energy industries (in the following formulas, $i, j=\mathrm{u}, \mathrm{e}, \mathrm{r}$.).

Major formulas are presented below:

(1) Commodity flow balance

Each industry must supply products to meet the economic demand of the entire country in the whole year. Products should maintain the balance between the the output and Intermediate inputs, final consumption, exports and imports.

$$
X_{u}(t) \geq A_{u u} X_{u}(t)+A_{u e} X_{e}(t)+A_{u r} X_{r}(t)+C_{u}(t)+G_{u}(t)+I_{u}(t)+E_{u}(t)-M_{u}(t)
$$

$X_{u}(t)$ : production of each sector in usual industry in term $t(e n)$

$A_{i j}$ : input coefficient from industry $i$ to industry $j$ (ex)

$C_{u}$ : household consumption of each sector in usual industry (en)

$G_{u}$ : government consumption in each sector in usual industry $(e x)$

$I_{u}:$ investment in each sector in usual industry (en)

$E_{u}$ : export of each sector in usual industry $(e x)$ 
$M_{u}:$ import of each sector in usual industry (en)

(2) Electricity supply and demand balance

The electricity flow balance module specifies the balance between electricity supply and demand. Electricity supply can be provided by three sources: thermal power, renewable power and imported power. Electricity demand is from the consumption of industries, household consumption and governmental consumption.

$$
d_{u} X_{u}(t)+d_{e} X_{e}(t)+d_{r} X_{r}(t)+d_{h} C_{h}(t)+d_{g} C_{g}(t)=S_{e}(t)+S_{r}(t)+S_{m}(t)
$$

$d_{i}$ : the electricity demand coefficient of each sector in industry $\mathrm{i}(e x)$

$d_{h}$ : the electricity demand coefficient of household (ex)

$d_{g}$ : the electricity demand coefficient of government $(e x)$

$S_{e}(t):$ the thermal power supplied in term $t(e n)$

$S_{r}(t)$ : the renewable power supplied in term $t$ (en)

$S_{m}(t)$ : the power imports from other regions in term $t$ (en)

(3) GHG emissions

GHG emissions means the total quantity including emissions by industries, household consumption and the untreatment of municipal waste. Among the $\mathrm{GHG}, \mathrm{CO}_{2}, \mathrm{CH}_{4}$ and $\mathrm{N}_{2} \mathrm{O}$ are included in the calculation.

$$
G H G(t)=e c_{u} X_{u}(t)+e c_{e} X_{e}(t)+e c_{r} X_{r}(t)++e c_{h} C_{(t)}+e c_{w} * Q_{w}(t)
$$

$G H G(t)$ : total amount of GHG emissions in term $t(e n)$

$e c_{i}$ : greenhouse gas emissions coefficient of each sector in industry $i(e x)$

$e c_{h}$ : greenhouse gas emissions coefficient of household consumption $(e x)$

$e c_{w}$ : greenhouse gas emissions coefficient of landfill waste $(e x)$

$Q_{w}$ : the quantity of landfill waste (en)

(4) Value flow balance

In the input-output table, output should be in accordance with the input between the industries, household income, depreciation, indirect tax, carbon tax and subsidies to renewable energy industries.

$$
\begin{aligned}
& P_{u}(t) X_{u}(t) \leq P_{u}(t) A_{u u} X_{u}(t)+P_{e}(t) A_{e u} X_{u}(t)+P_{r}(t) A_{r u} X_{u}(t)+Y_{h u}(t)+\alpha_{u} K_{u}(t)+\beta_{u} X_{u}(t)+\delta_{c} e c_{u} X_{u}(t) \\
& P_{e}(t) X_{e}(t) \leq P_{u}(t) A_{u e} X_{e}(t)+P_{e}(t) A_{e e} X_{e}(t)+P_{r}(t) A_{r e} X_{e}(t)+Y_{h e}(t)+\alpha_{e} K_{e}(t)+\beta_{e} X_{e}(t)+\delta_{c} e c_{e} X_{e}(t) \\
& P_{r}(t) X_{e}(t)+S U B(t) \leq P_{u}(t) A_{u r} X_{r}(t)+P_{e}(t) A_{e r} X_{r}(t)+P_{r}(t) A_{r r} X_{r}(t)+Y_{h r}(t)+\alpha_{r} K_{r}(t)+\beta_{r} X_{r}(t)+\delta_{c} e c_{r} X_{r}(t) \\
& S U B(t)=\delta_{c} e c_{u} X_{u}(t)+\delta_{c} e c_{e} X_{e}(t)
\end{aligned}
$$

$P_{i}:$ price rate of each sector in industry $i(e n)$

$Y_{h i}$ : household income of each sector in industry $i(e n)$

$\alpha_{i}$ : depreciation rate of each sector in industry $i(e x)$

$\beta_{i}$ : indirect tax rate of each sector in industry $i(e x)$

$\delta_{c}:$ carbon tax $(e x)$

$S U B$ : subsidies to renewable power industries (en).

(5) Investment and saving balance

In the model, investment and saving blance describes the macroeconomic module in different economy entities. Since there are four economy entities in this model, including household, government, industry, and other inter-regional trade, it satisfies the macroeconomic law of four-sector economy: investment on industries plus net trade is equal to the saving in household and government.

$$
\begin{aligned}
& \left\{I_{u}(t)-\alpha_{u} K_{u}(t)\right\}+\left\{I_{e}(t)-\alpha_{e} K_{e}(t)\right\}+\left\{I_{r}(t)-\alpha_{r} K_{r}(t)\right\} \\
& +E_{u}-M_{u}(t)+E_{e}-M_{e}(t) \leq S A_{h}(t)+S A_{g}(t)
\end{aligned}
$$

$k_{i}$ : the capital stock of each sector in industry $i(e n)$

$S A_{h}(t)$ : household saving in term $t(e n)$ 
$S A_{g}(t)$ : government saving in term $t(e n)$

(6) Dynamic Equation of Capital Stock

In the model, the capital stock in term $(t+1)$ is related to the capital stock and the investment in the last term. So the capital stock of each industry is specified as follows:

$$
\begin{aligned}
& K_{u}(t+1)=\left(1-\alpha_{u}\right) K_{u}(t)+I_{u}(t) \\
& K_{e}(t+1)=\left(1-\alpha_{e}\right) K_{e}(t)+I_{e}(t) \\
& K_{r}(t+1)=\left(1-\alpha_{r}\right) K_{r}(t)+I_{r}(t)
\end{aligned}
$$

(7) Objecive function

The objective function is to maximize GRP from 2010 to 2025 in Beijing:

$$
\begin{gathered}
M A X=\sum_{t=1}^{16} G R P(t) \\
G R P(t)=V_{u} X_{u}(t)+V_{e} X_{e}(t)+V_{r} X_{r}(t)
\end{gathered}
$$

$G R P(t)$ : the gross regional production in term $t$ (en)

$V_{i}$ : the value-added rate of each sector in industry $i(e x)$

\subsection{Data Sources}

In this paper, Beijing's economic input-output table 2010 and the data of municipal waste is obtained from the Beijing Bureau of Statistics. The data of energy consumption in each setor is obtained from Beijing Statistical Yearbook (Beijing Municipal Bureau of Statistics, 2011). The amount of $\mathrm{CO}_{2}$ emited by the different types of fossil energy can be calculated based on the emission coefficient from IPCC. Besides, the parameters of the renewable energy industries are processed based on the data collected from the registered CDM (Clean Development Mechanism) projects. Database can be obtained from authors upon request.

\subsection{Case Setting}

In this model, we set up three cases. The first is the baseline case, which is a simulation without GHG emissions constraint. In case 1 and case 2, the same greenhouse gases emissions constraint will be constructed. GHG emissions in term $\mathrm{t}$ are less than $\mathrm{n}$ times of that in base year $(\mathrm{n}=1.4-2.0)$.

Table 2. GHG emissions constraints

\begin{tabular}{cccc}
\hline & $\begin{array}{c}2015: \\
\text { GHG intensity } \\
\left(\mathrm{t} \mathrm{CO}_{2} \text {-e/million CNY) }\right.\end{array}$ & $\begin{array}{c}2020 / 2010: \\
\text { GRP }\end{array}$ & $\begin{array}{c}2010-2025: \\
\text { average growth rate } \\
\text { of GRP }\end{array}$ \\
\hline $\mathrm{n}=2.0$ & 59.7 & $250 \%$ & $7.7 \%$ \\
$\mathrm{n}=1.9$ & 58.7 & $241 \%$ & $7.4 \%$ \\
$\mathrm{n}=1.8$ & 57.9 & $233 \%$ & $7.1 \%$ \\
$\mathrm{n}=1.7$ & 56.8 & $225 \%$ & $6.6 \%$ \\
$\mathrm{n}=1.6$ & 54.7 & $215 \%$ & $6.2 \%$ \\
$\mathrm{n}=1.5$ & 53.1 & $201 \%$ & $5.8 \%$ \\
$\mathrm{n}=1.4$ & 49.2 & $193 \%$ & $5.3 \%$ \\
\hline
\end{tabular}

As indicated in Table 2, when we choose $\mathrm{n}=1.5$ times, the result not only satisfies the government's environmental objective in 2015 (reducing 18\% of $\mathrm{CO}_{2}$ emission per unit of GRP with compared with 2010 level), but also achieves the governmental economic target in 2020 (GRP will be doubled by 2010). Thus, case 1 is set only based on the GHG constraint. In case 2, renewable energy industries and carbon tax are introduced into the model. According to the Beijing's economic level, we set the carbon tax as $80 \mathrm{CNY} / \mathrm{t} \mathrm{CO}_{2}$-e, the same as the price of a certificated emission reduction (CER) in the CDM market. The carbon tax is an oriented tax that promote the utilization of renewable energy. 
Table 3. Case setting

\begin{tabular}{ccc}
\hline & $\begin{array}{c}\text { Greenhouse gas emissions constraint } \\
(\mathrm{n}=1.5 \text { times })\end{array}$ & Environmental tax \\
\hline Baseline & Without & Without \\
case 1 & With & Without \\
case 2 & With & With \\
\hline
\end{tabular}

\section{Simulation Results and Discussion}

\subsection{Economic Developing Trend in Three Cases}

As is shown in Figure 4, without the constraint, GRP will increase very fast in Baseline case. In case 1 and case 2, we used the same greenhouse gas emissions constraint, 150 million ton of $\mathrm{CO}_{2}$, which is 1.5 times of the 2010 level. Comparing the GRP in case 1 and case 2, it is found that the introduction of carbon tax as $80 \mathrm{CNY}_{\mathrm{t}} \mathrm{CO}_{2}$-e will lead to the increase of the total GRP from 2010 to 2025 by 1,307 billion CNY. It can be proved that the introduction of carbon tax will promote the economic development in study area.

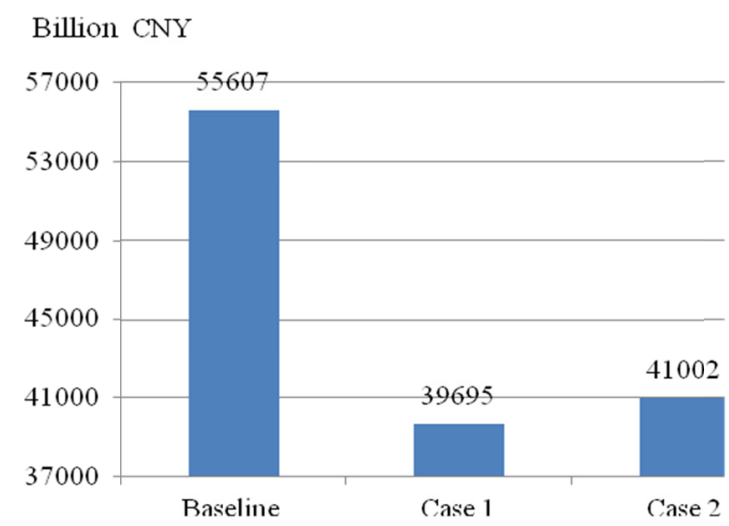

Figure 4. Total GRP from 2010 to 2025

\subsection{GHG Intensity in Three Cases}

In 2011, Beijing government published the“12th Five-Year Plan of Economic and Social Development”, one of whose objectives is to make $\mathrm{CO}_{2}$ emission per unit GRP resduce $18 \%$ compared with 2010 level. As indicated in Figure 5, in 2010, Beijing's greenhouse gas emissions intensity is $71.1 \mathrm{t} \mathrm{CO}_{2}$-e/million CNY. Thus, the GHG intensity should be below $58.3 \mathrm{t} \mathrm{CO}_{2}$-e/million CNY in 2015. As showed in figure 5, in 2015, the greenhouse gas emissions intensity in baseline case is much larger than the government's target. Although the GRP in the baseline case increase greatly, it is difficult to realize the government's environmental objectives. With the GHG emissions constraint, the GHG intensity is 53.0 and $52.5 \mathrm{t} \mathrm{CO}_{2}-\mathrm{e} / \mathrm{million} \mathrm{CNY}$ in case 1 and case 2 respectively, which can meet the government's requirement. With the introduction of the $80 \mathrm{CNY} / \mathrm{t} \mathrm{CO}_{2}$-e carbon taxe, the GHG intensity in case 2 is smaller than in case 1 in each year. 


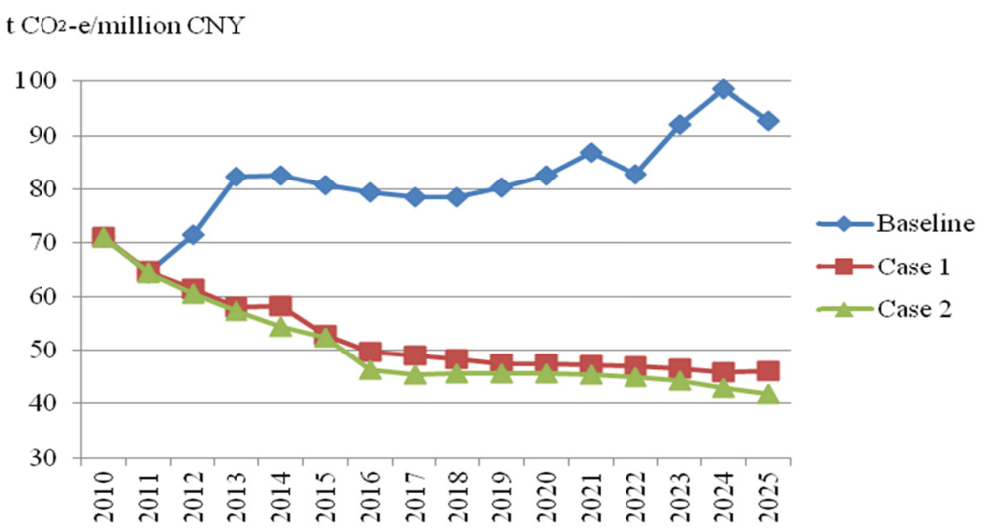

Figure 5. GHG intensity from 2010 to 2025

\subsection{Economic Development and GHG Intensity in Case 2}

As indicated in figure 6, with the greenhouse gas emissions constraint as 1.5 times larger than the 2010 level and the carbon tax as $80 \mathrm{CNY} / \mathrm{t} \mathrm{CO}$-e, annual growth rate of GRP can be up to $6.4 \%$. The economic growth rate increases $0.6 \%$ compared with the condition when not introducing the policy instrument. GHG intensity is an important environmental indicator, which can reflect the relationship between the GHG emissions amount and economic growth rate. In 2025, the GHG intensity will be $41.8 \mathrm{t} \mathrm{CO}_{2}$-e/million $\mathrm{CNY}, 41.4 \%$ reduced compared with the 2010 level.

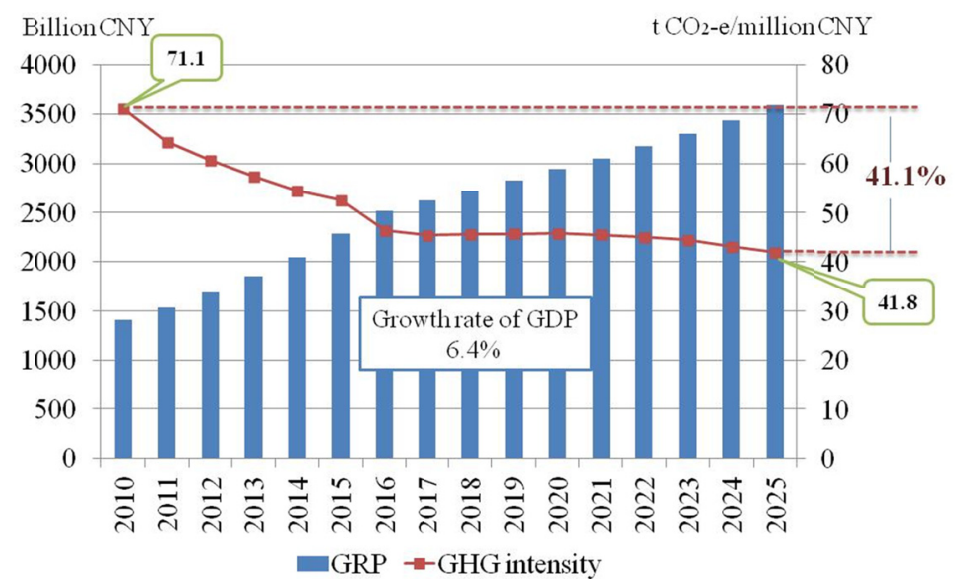

Figure 6. Trend of GRP and GHG intensity in case 2

\subsection{Energy System Transformation}

With the subsidy from carbon tax, the renewable energy power generation will increase. As indicated in Figure 7, total electricity generation of biomass power is $22.2 \mathrm{GWh}$, wind power is $9.2 \mathrm{GWh}$, and solar power is $9.5 \mathrm{GWh}$. The carbon tax from 2010 to 2025 which is used as subsidy to the renewable energy industries is 135 billion $\mathrm{CNY}$. Total power generation of renewable energy can be $40.9 \mathrm{GWh}$, contributing to the reduction of 25 million $\mathrm{CO}_{2}$-e emissions in 15 years. However, as indicated in figure 8, thermal power still occupies the dominant position in the electricity production structure in Beijing. The share of renewable energy power is $9 \%$ in 2020 . 


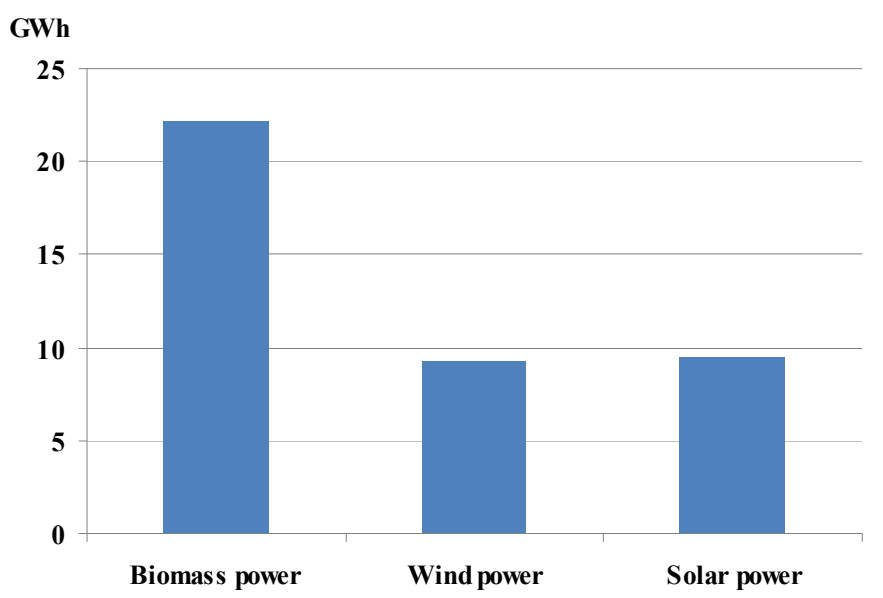

Figure 7. Renewable energy power generation in Beijing from 2010 to 2025

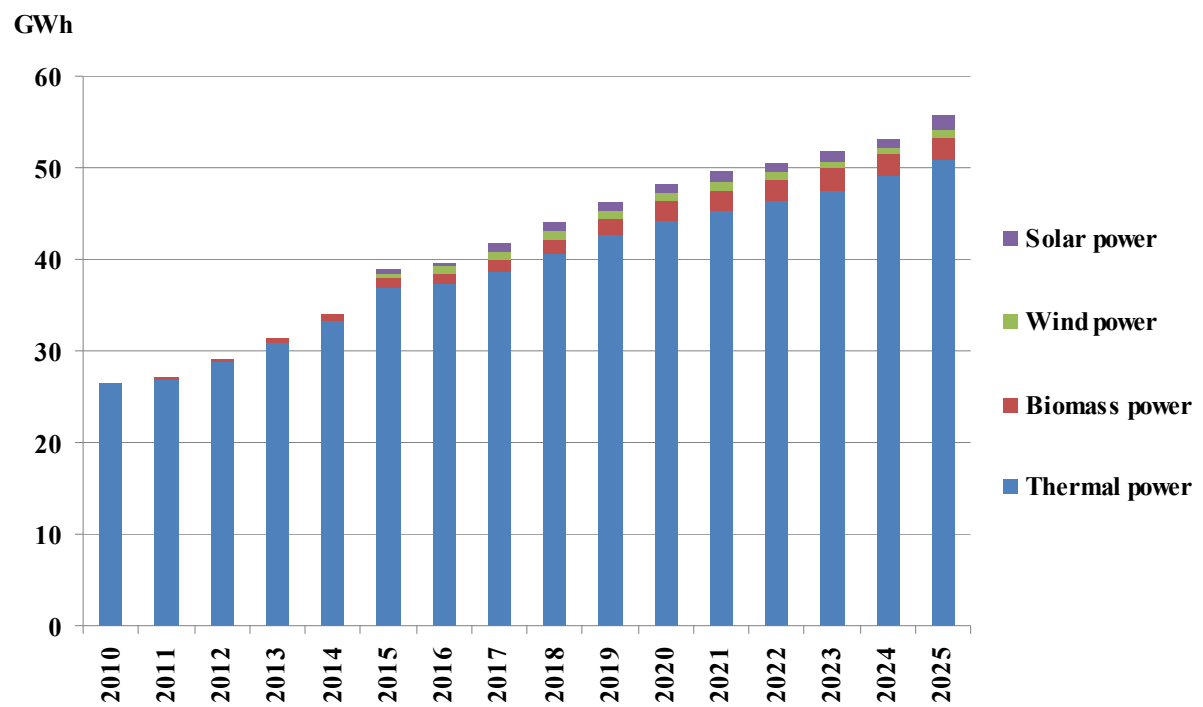

Figure 8 . Structure of electricity production in case 2

\section{Conclusion}

In China, each region is facing the contradiction of GRP growth and GHG mitigation. Beijing governmet issued the target of mitigating the GHG intensity and the enhance growth of GRP. The objective is to reduce $18 \%$ of $\mathrm{CO}_{2}$ emission per unit of GRP compared with 2010 level by 2015 (Beijing Municipal Commission of Development and Reform, 2011b). In 2020, GRP will be doubled by 2010. In this context, we constructed an extended model to evaluate the environmental tax's effects, with introduction of carbon tax as $80 \mathrm{CNY} / \mathrm{t} \mathrm{CO} \mathrm{CO}_{2}$-e.

The simulation results proved that the introduction of the environmental tax is effective to promote the utilization of renewable energy, realize the governmet's economic target and decrease the GHG intensity. It can be a successful example to other regions. Firstly, utilization of renewable energy increases greatly with total power generation from renewable energy as $40.9 \mathrm{GWh}$, contributing to the reduction of 25 million $\mathrm{CO}_{2}$-e emissions in 15 years. The proportion of renewable energy power can be $9 \%$ in 2025 . Secondly, with the greenhouse gas emissions constraint as 1.5 times of the 2010 level and the carbon tax as $80 \mathrm{CNY} / \mathrm{t} \mathrm{CO}$-e, it will lead to the increase of the total GRP from 2010 to 2025 by 1,307 billion CNY. Annual growth rate of GRP can be up to $6.4 \%$. The economic growth rate increases $0.6 \%$ compared with the condition when not introducing the policy instrument. It can be proved that the introduction of carbon tax will promote the economic development in study area. Finally, GHG intensity is an important environmental indicator, which can reflect the relationship between the GHG emissions amount and economic growth rate. In 2015, the GHG intensity will be $52.8 \mathrm{t}$ $\mathrm{CO}_{2}$-e/million CNY, 25\% reduced compared with 2010 level. In 2025, the GHG intensity will decrease to $41.8 \mathrm{t}$ $\mathrm{CO}_{2}$-e/million $\mathrm{CNY}, 41.4 \%$ reduced compared with the 2010 level. 
In this paper, there are some aspects needed to be improved. First, Beijing is rich in geothermal resources which can be used to produce heat, leading to reduction of the fossil energy consumption in heat industry. Meanwhilae, in terms of the renewable resources in this paper, they are only utilized to produce the electricity. However, they can be utilized in other directions, such as production of biomass oil, generation of solar thermal and so on. In addition, with repect to carbon tax, only carbon tax of $80 \mathrm{CNY} / \mathrm{t} \mathrm{O}_{2}$-e is introduced. In the future studies, it different levels of carbon tax (such as $50 \mathrm{CNY} / \mathrm{t} \mathrm{CO}_{2}$-e, $100 \mathrm{CNY} / \mathrm{CO}_{2}$-e) will be set and scenarios will be simulated to select the optimal tax rate for Beijing city.

\section{Acknowledgements}

This research is supported by the "National Project of the Construction High Level University" of the Chinese Scholarship Council. We would like to give appreciation to Dr. Junnian Song, who is studying in University of Tsukuba for his valuable suggestions.

\section{References}

Beckman, J., Hertel, T., \& Tyner, W. (2011). Validating energy-oriented CGE models. Energy Economics, 33(5), 799-806. http://dx.doi.org/10.1016/j.eneco.2011.01.005

Beijing Municipal Bureau of Statistics. (2011). Beijing Statistical Yearbook. Beijing: Beijing Bureau of Statistics.

Beijing Municipal Commission of Development and Reform. (2011a). 12th Five Year Plan for the New Energy and Renewable Energy Development of Beijing. Retrieved from http://www.bjpc.gov.cn/fzgh_1/guihua/12_5/12_5_zx/12_5_yb/125_yb_csjs/201108/U0201112283798138 55679.doc

Beijing Municipal Commission of Development and Reform. (2011b). 12th Five Year Plan for the National Economic and Social Development of Beijing. Retrieved from http://www.bjpc.gov.cn/fzgh_1/guihua/12_5/sewghgy/125_dyp/201108/t840331.htm

Dhakal, S. (2009). Urban energy use and carbon emissions from cities in China and policy implications. Energy Policy, 37(11), 4208-4219. http://dx.doi.org/10.1016/j.enpol.2009.05.020

Dincer, I. (2000). Renewable energy and sustainable development: a cruial review. Renewable and Sustainable Energy Review, 4(2), 157-175. http://dx.doi.org /10.1016/S1364-0321(99)00011-8

Labriet, M., Kanudia, A., \& Loulou, R. (2012). Climate mitigation under an uncertain technology future: A TIAM-World analysis. Energy Economics, 34(3), 366-377. http://dx.doi.org/10.1016/j.eneco.2012.02.016

Liang, Q. M., \& Wei, Y. M. (2012). Distributional impacts of taxing carbon in China: Results from the CEEPA model. Applied Energy, 92, 545-551. http://dx.doi.org/10.1016/j.apenergy.2011.10.036

Lu, C. Y., Tong, Q., \& Liu, X. M. (2010). The impacts of carbon tax and complementary policies on Chinese economy. Energy Policy, 38(11), 7278-7285. http://dx.doi.org/10.1016/j.enpol.2010.07.055

Oliveria, C., \& Antunes, C. H. (2004). A multiple objective model to deal with economy-energy-environment interactions. European Journal of Operational Research, 153(2), 370-385. $\mathrm{http}: / / d x . d o i . o r g / 10.1016 / \mathrm{S} 0377-2217(03) 00159-0$

Potočnik, J. (2007). Renewable Energy Sources and the Realities of Setting an Energy Agenda. Science, 315(5813), 810-811. http://dx.doi.org/10.1126/science.1139086

Raa, T. T. (2009). Input-output economics: theory and applications: featuring Asian economies. Singapore: World Scientific.

Rout, U. K., Alfred Voß, A., Singh, A., Fahl, U., Blesl, M., \& Gallachoir, B. P. (2011). Energy and emissions forecast of China over a long-time horizon. Energy, 36(1), 1-11. http://dx.doi.org/10.1016/j.energy.2010.10.050

Uchida, S., \& Higano, Y. (2006). An Evaluation of Policy Measures against Global Warming by promoting effective use of potential energy in wastes. Studies in Regional Sciences, 36(1), 481-508.

Wei, Z. X., Li, W. J., \& Wang, T. (2011). The Impacts and Countermeasures of levying Carbon Tax in China under Low-carbon Economy. Energy Procedia, 5, 1968-1973. http://dx.doi.org/10.1016/j.egypro.2011.03.338

Wiedmann, T. (2009). A review of recent multi-region input-output models used for consumption-based emission $\begin{array}{llll}\text { and } & \text { resources }\end{array}$ http://dx.doi.org/10.1016/j.ecolecon.2009.08.026 
Yang, C., Wang, F., \& Men, M. (2011). Analyzing the impacts of carbon taxes on CO2 emissions and macroeconomics. Statistical Research, 28(7), 45-54.

Zhang, L. X., Feng, Y. Y., \& Chen, B. (2011). Alternative scenarios for the development of a low-carbon city: a case study of Beijing, China. Energies, 4(12), 2295-2310. http://dx.doi.org / 10.3390/en4122295

Zhang, J. Y., Zhang, Y., Yang, Z. F., Fath, B. D., \& Li, S. S. (2013). Estimation of energy-related carbon emissions in Beijing and factor decomposition analysis. Ecological Modeling, 252, 258-265. http://dx.doi.org/10.1016/j.ecolmodel.2012.04.008

\section{Copyrights}

Copyright for this article is retained by the author(s), with first publication rights granted to the journal.

This is an open-access article distributed under the terms and conditions of the Creative Commons Attribution license (http://creativecommons.org/licenses/by/3.0/). 